\title{
Restoring Esthetics and Function in worn anterior teeth using Dahl Priniciple - A Series of 3 case reports
}

\author{
Karthickraj $\mathrm{M}^{1}$ \\ ${ }^{1}$ Saveetha University Saveetha Dental College
}

May 26, 2020

\begin{abstract} reports

Author details:

Dr Karthickraj S M, MDS

Senior Lecturer

Saveetha Dental College

Chennai

Corresponding Author Details:

Dr Karthickraj S M

No. 17/5A VOC Nagar I Street,

Kaladipet,

Chennai-600019,

$+91-9840094540$
\end{abstract}

Case series was done to discuss the use of cemented dahl appliance for increasing the occlusal vertical dimension (OVD) and effectively restore esthetics and function in worn anterior teeth.

Title: Restoring Esthetics and Function in worn anterior teeth using Dahl Priniciple - A Series of 3 case

Karthickraj91@gmail.com

Disclosure Statement:

The author do not have any financial interest in the companies whose materials are included in this article 

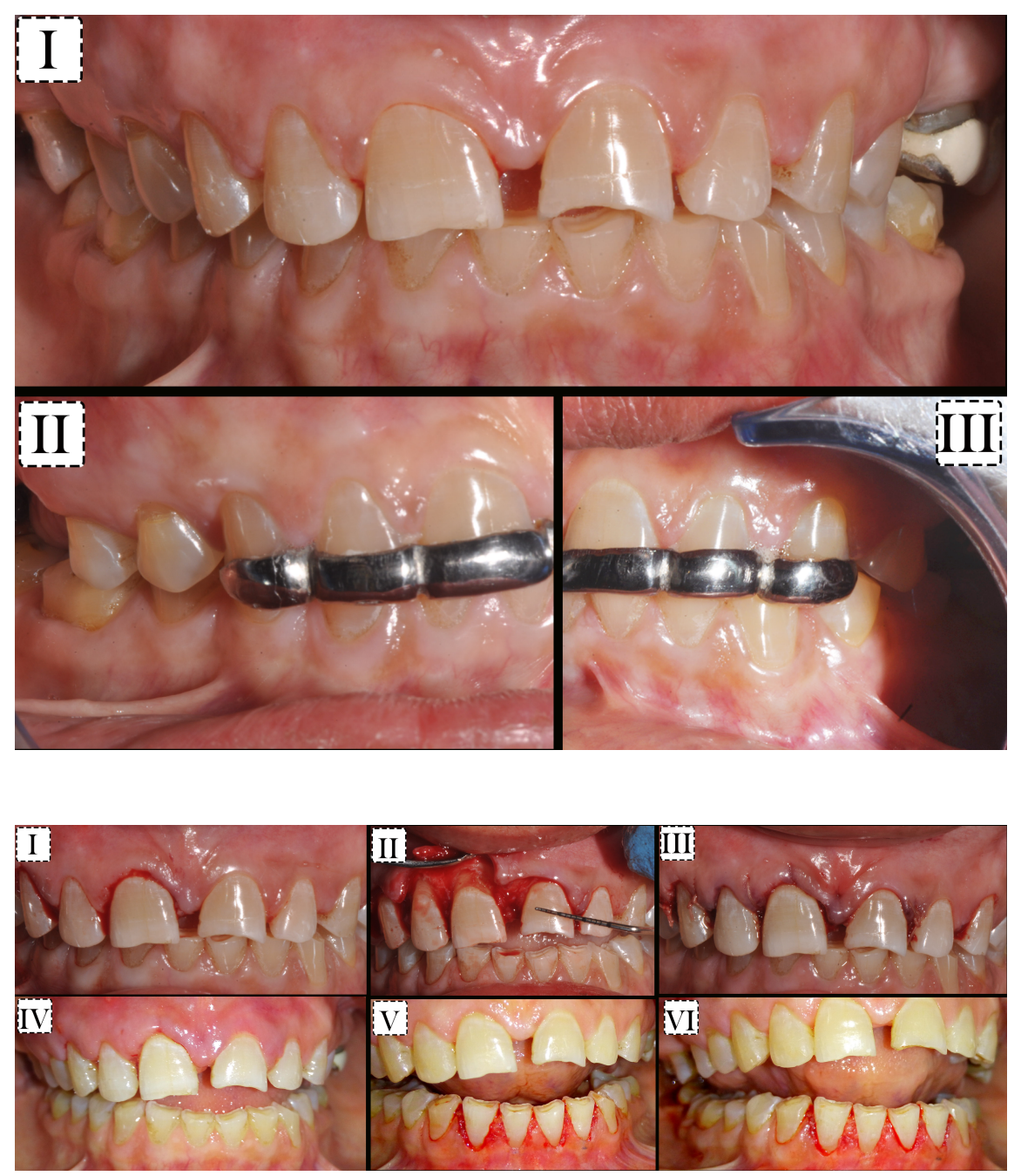


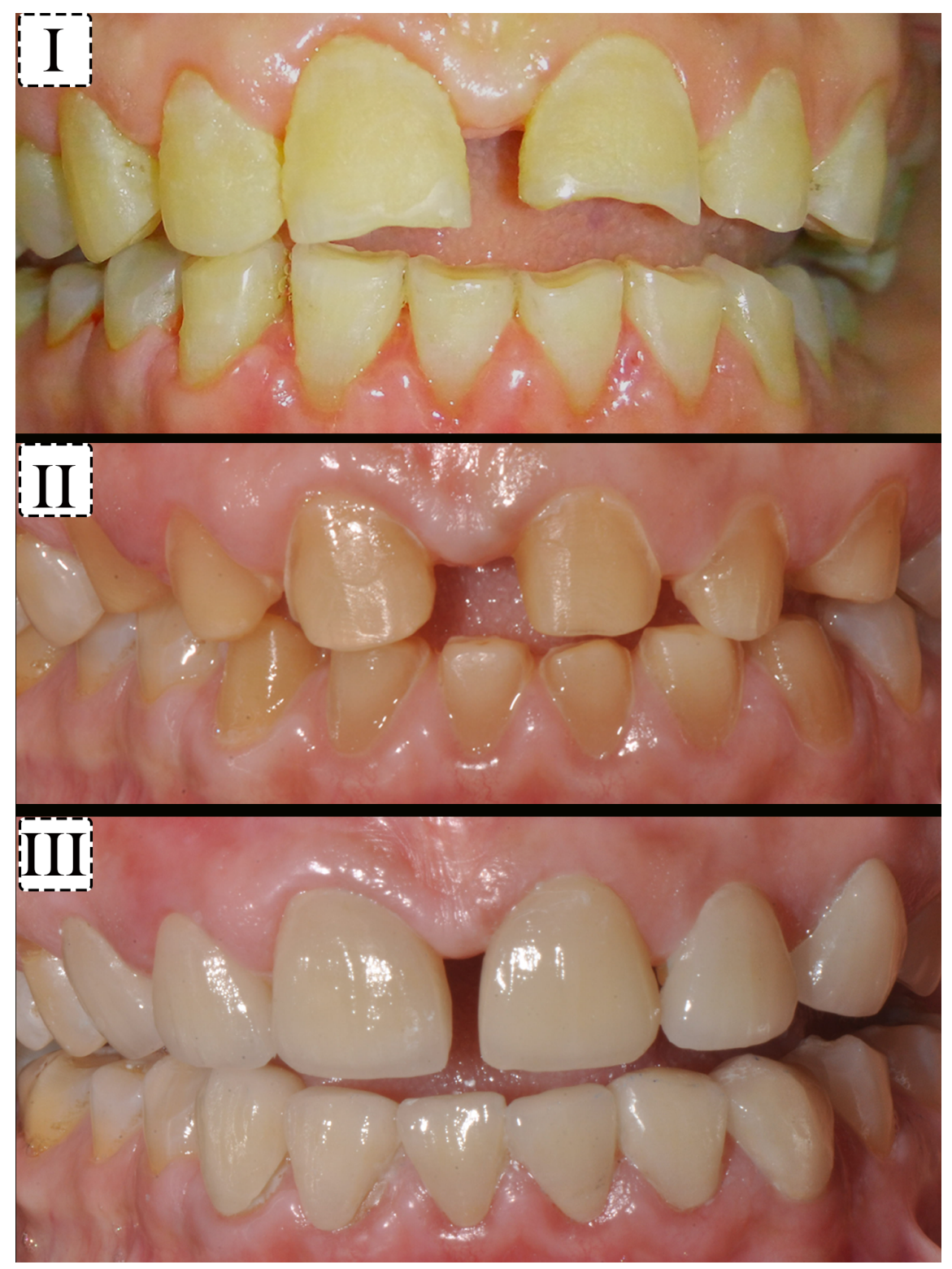



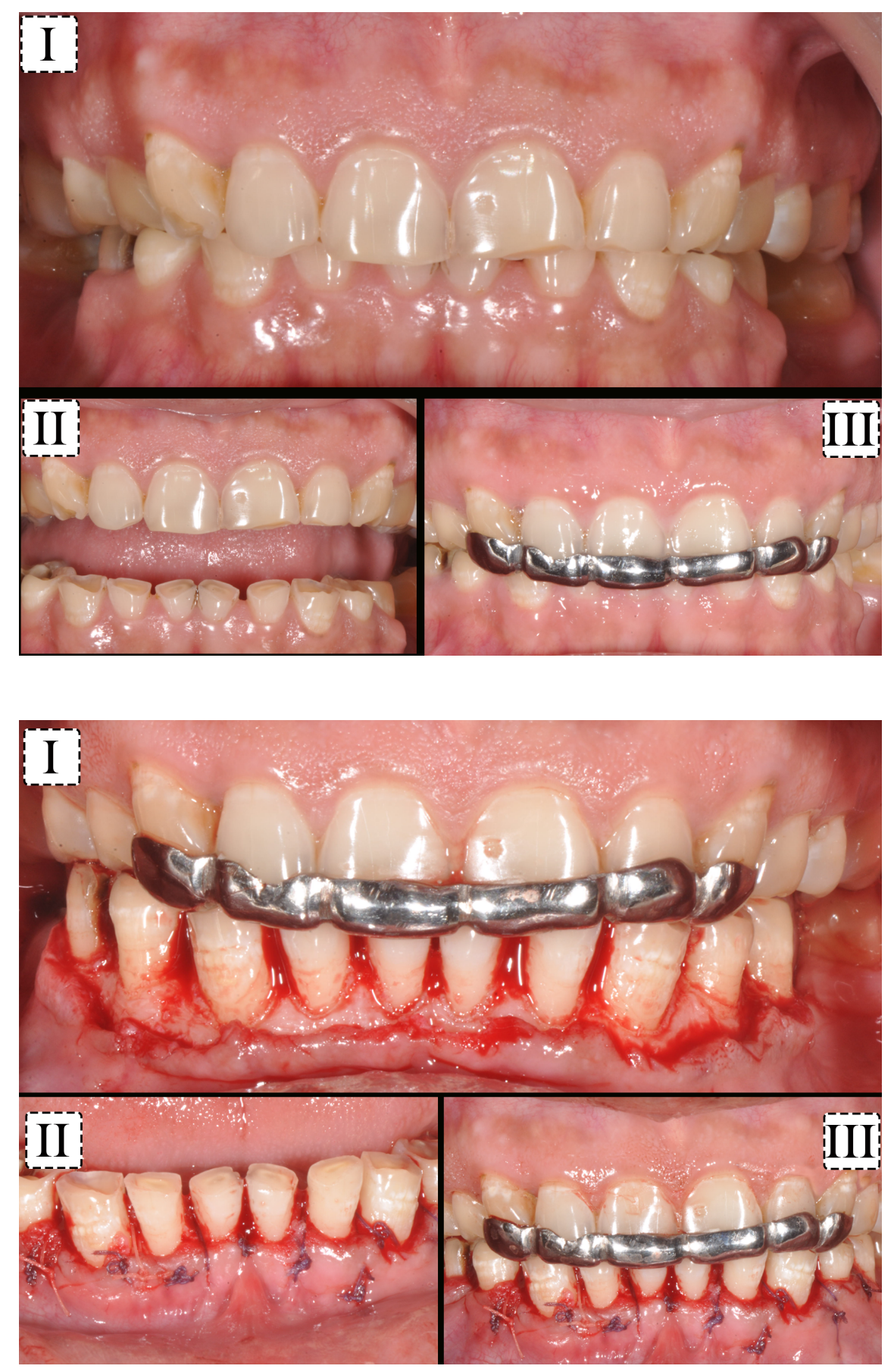

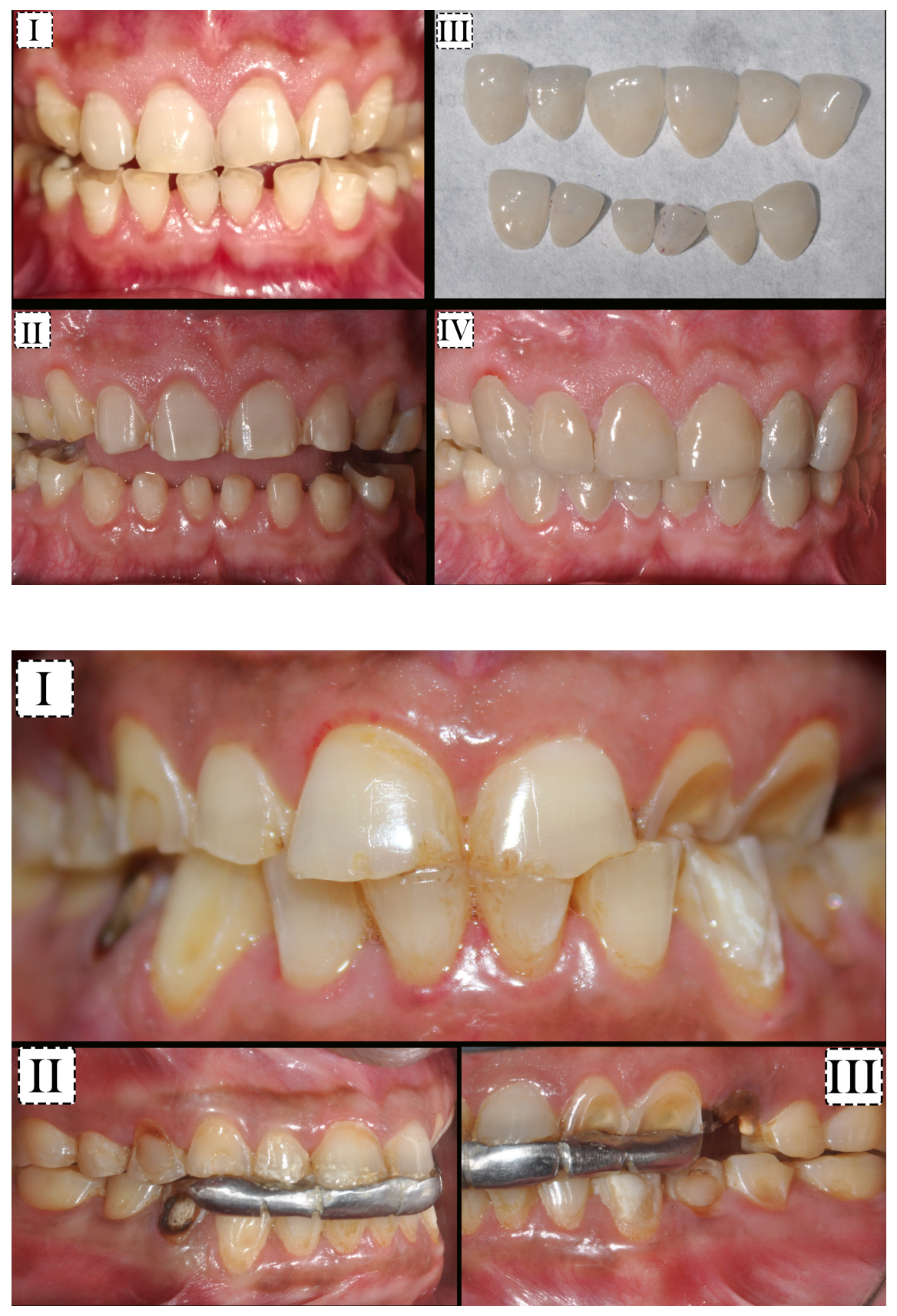


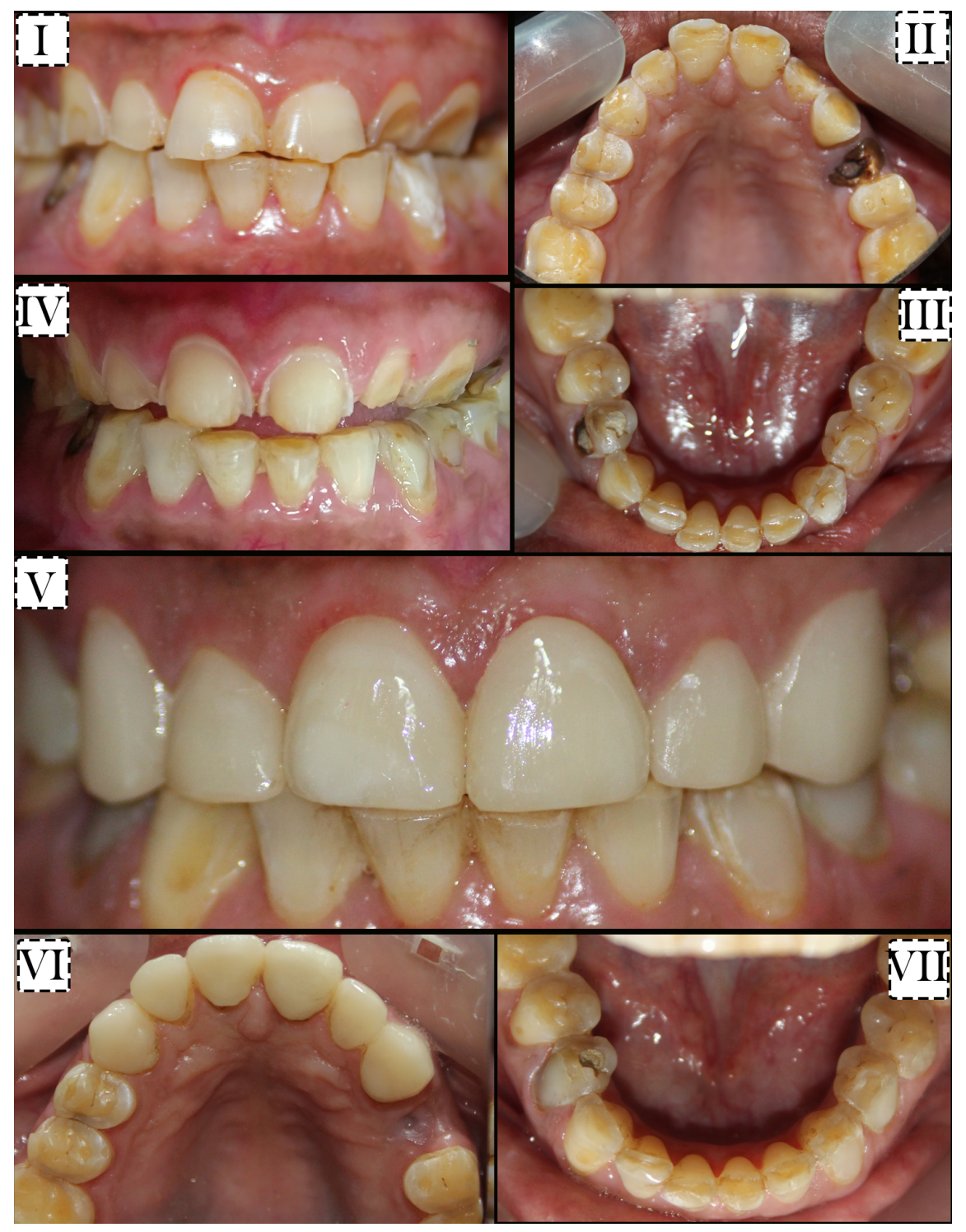

